\title{
Chemical concepts inventory of Grade 12 learners and UP foundation year students
}

\author{
M. Potgieter ${ }^{1}$, J. M. Rogan ${ }^{2}$ and S. Howie ${ }^{1}$ \\ ${ }^{1}$ University of Pretoria, South Africa \\ ${ }^{2}$ University of KwaZulu-Natal, South Africa \\ mpotgieter@postino.up.ac.za;jmroganza@yahoo.com; showie@postino.up.ac.za
}

\begin{abstract}
Incoming chemistry students at tertiary institutions have a variety of academic backgrounds that influence their prospects of success at first-year level. The proficiencies of incoming students are currently changing due to the introduction of outcomes-based education and new syllabi for physical science in secondary schools. In order to ensure a smooth transition from secondary to tertiary education, university lecturers should be well informed about the content knowledge, conceptual understanding and skills development of prospective first-year students. This study evaluates the proficiencies of Grade 12 learners in physical science in terms of a number of clearly identified problem areas: conceptual understanding, logical scientific reasoning, basic mathematical ability, knowledge of subject content and scientific process skills. A test instrument was developed that consisted mainly of conceptual questions rather than recall or algorithmic items. Paired questions (two-tier methodology) and pictorial representations were used extensively. A follow-up question about certainty of response was included for all fixed-response items in order to evaluate the influence of guessing on response distributions. The test instrument was administered at the end of the third term to Grade 12 learners taking Physical science at three schools in privileged environments (1 English and 2 Afrikaans medium) and four township schools, and to all University of Pretoria Foundation Year (UPFY) students.
\end{abstract}

Analysis of results highlighted the generally poor performance of students from township schools and the significant improvement in performance after one year of intensive instruction of UPFY students, who generally came from similar or more impoverished backgrounds. The poor performance for all cohorts on basic concepts, such as the mole concept, stoichiometry and the limiting reagent, as well as on several special topics, indicates that students lack a sound basis for tertiary chemistry. Of real concern is the evidence of over-confidence obtained from the certainty of response analyses. This result indicates that respondents failed to judge the complexity and level of difficulty of questions accurately. Learners/students from all groups displayed weak understanding of events at molecular level. In order to address this situation, lecturers at tertiary level will have to actively promote conceptual understanding of all basic concepts in chemistry and resist the temptation to teach and assess mainly procedural fluency. Analysis of certainty of response data showed that the guess factor was less serious a complication than anticipated.

\section{Introduction}

Tertiary institutions have the obligation to train future professionals in an efficient and costeffective manner. In order to ensure a smooth transition from secondary to tertiary education, university lecturers should be well-informed about the content knowledge, conceptual understanding and skills development of prospective first-year students. This issue is of specific relevance in view of the imminent changes in government funding formulae for tertiary institutions. 
Incoming chemistry students at tertiary institutions have a variety of academic backgrounds that influence their prospects of success at first-year level. The majority of the current intake of students has been instructed according to the previous syllabi of the provincial Departments of Education with an accompanying set of proficiencies that were fairly well known. The situation is changing rapidly, however, due to a variety of factors associated with the introduction of Outcomes-based Education as well as a new syllabus for physical science to secondary schools in South Africa.

This paper reports on a study undertaken at neighbouring secondary schools of the University of Pretoria (UP) with the objective to draw up a Chemical Concepts Inventory for Grade 12 learners upon exit from secondary education. It served as the pilot study for a larger project that is being undertaken to monitor the preparedness of first-year students for chemistry at tertiary level during the current transition period.

This study addresses the following research questions:

- To what extent have learners mastered conceptual understanding of basic chemical concepts upon exit from secondary schools?

- How well are Grade 12 physical science learners prepared for first-year chemistry in terms of assumed pre-knowledge?

- Are learners/students able to interpret symbolic representations and macroscopic effects in terms of events at the molecular level?

- To what extent have UPFY students overcome the deficiencies of their secondary school chemistry background upon exit from the programme?

- Does guessing influence the frequency distribution obtained for multiple-choice items, thereby comprising its interpretation?

- How competent are learners/students to judge their own performance in chemistry?

Conceptual understanding is a highly valued learning outcome for the teaching community, but it is not easily assessed, especially in large student groups. A distinction can be made between algorithmic questions (questions that can be answered by applying a set procedure to generate a response) and conceptual questions (probing the depth of understanding of the chemical concepts related to a question) (Bowen \& Bunce, 1997). Algorithmic questions typically require lower order cognitive skills (Zoller et al., 2002). Solving numerical (algorithmic) problems does not imply conceptual understanding of the problems. Yarroch (1985) and Lythcott (1990) reported that over half of the students who correctly solved stoichiometric problems were unable to exhibit a conceptual understanding consistent with the notation of the question. Several authors have reported that about one third of students choosing the correct option in a multiple-choice question do so for a wrong reason (Treagust, 1988; Tyson et al., 1999; Voska \& Heikkinen, 2000). A suitable test instrument for the assessment of proficiencies of chemistry students/learners should consist mainly of conceptual questions and provide opportunities for explanation of answers to multiple-choice questions (two-tier methodology developed by Treagust, 1988).

A deep understanding of chemistry involves being able to link what one observes in the laboratory (the macroscopic level) to what one imagines is happening to substances at the invisible molecular or particulate level. Only then can these ideas be communicated meaningfully using abstract chemical symbolism, terminology and mathematics (the symbolic level). The "three thinking levels" approach, first described by Johnstone and El-Banna (1986) encourages students to learn new chemistry concepts by thinking about them at these macroscopic, molecular and symbolic levels. Science teaching at secondary schools in South Africa occurs mainly at the symbolic level due to the lack of adequate teaching resources. 
Textbooks contain two-dimensional diagrams that are often over-simplified or inadequate and the vast majority of secondary schools do not have suitably equipped laboratories. There is convincing evidence that most students' difficulties and misconceptions in chemistry stem from inadequate or inaccurate models of the molecular world (Lijnse et al., 1990). An important aspect of successful problem solving in chemistry involves "representational competence", i.e. the ability to use multiple representations and to transform representations in one form to equivalent representations in another (Bowen, 1998; Kozma \& Russell, 1997). A suitable test instrument for the assessment of proficiencies of grade 12 learners in physical science and incoming first-year students in chemistry should engage all three thinking levels and should allow the researcher/lecturer to identify deficiencies at each of them.

It is well documented that mathematical aptitude is one of the strongest predictors of success in first-year general chemistry, followed by a basic knowledge of chemistry concepts (McFate \& Olmsted, 1999; Wagner et al., 2002). There are, however, a number of non-cognitive factors such as study habits (consistent work), motivation (interest and desire to understand presented material), and self-confidence that may be equally or more important in the prediction of student success (Angel \& LaLonde, 1998). The instrument designed for this study did not include any non-cognitive factors, but an attempt was made to assess basic mathematical proficiency as required for first-year chemistry.

Hasan et al. (1999) used a certainty of response index in physics to distinguish between students' embedded misconceptions and their lack of knowledge. In this study an attempt was made to use self-reported certainty of response to evaluate the influence of guessing on the response pattern obtained for multiple-choice items. It was also used as an indication of selfefficacy, which provided insight into the competence of learners/students to judge their own performance in chemistry. Self-efficacy is a judgement of personal capability, a contextspecific assessment of competence to perform a specific task (Pajares, 1997, p. 15). Selfefficacy is a strong predictor of behaviour. Students with higher self-efficacy will put in greater effort to accomplish difficult tasks and will display more persistence in the face of setbacks (Hoy, 2004). On the other hand, an overly optimistic appraisal of ability to perform a task successfully may limit reflection and re-evaluation of problem-solving approaches, resulting in poor performance.

\section{Method}

\section{Test instrument}

A test instrument consisting of 80 test items was used for this study. The majority of these items were obtained from literature sources. Nineteen items from a multiple-choice test instrument developed by Mulford \& Robinson (2002) for the determination of the extent of alternate conceptions about specific core first-year chemistry topics were included. Conceptual questions on the mole concept (Krishnan \& Howe, 1994), chemical equilibrium (Huddle, 1998), solution chemistry (Smith \& Metz, 1996), and electrochemistry (Ogude \& Bradley, 1994) were included. The items with best correlation with student performance from the Student Pre-semester Assessment test (17 items) (Wagner et al., 2002) and the CSUF Placement test (6 items) (McFate \& Olmsted, 1999) were also included.

Twenty-two of the 80 test items were paired to provide opportunity for explanation of previous answers (two-tier methodology, Treagust, 1988). A significant number of pictorial representations were used (19 items). The majority of test items were in a multiple-choice (66 items, $83 \%$ ) or true/false format ( 2 items). The remainder of the items were short answer questions (10 items, 13\%) or self-constructed drawings (2 items), which were assessed and coded by the examiner. All multiple-choice and five of the short answer items were followed 
by a certainty of response index (CRI) where candidates indicated on a scale of 4 their confidence about the correctness of their answer [certain (4), almost certain (3), almost a guess (2) or a totally guessed answer (1)]. For the interpretation of results the 80 test items were grouped in 12 subsets covering nine chemistry content topics and three types of scientific skills (Table 2, discussed in next section). Six test items are included in the Appendix as specific examples. All other test items can be obtained from the principle author by correspondence.

\section{Reliability}

The internal consistency of the instrument was determined for each sample group using a subtest that consisted of 20 test items. The Cronbach alpha coefficients computed with SPSS software are listed in Table 1. Since the reliability coefficient depends in part on the length of the test, the numbers shown in Table 1 would have been larger had it been possible to include a greater number of items. The reliability for township schools is very low. The most likely reason is that most of the answers given were pure guesses. The subsequent analysis of the results (Table 2) reinforces this suspicion, since most of the averages were no higher than the level one would obtain by guessing. The reliability for the other two groups is more acceptable, especially in the light of the fact that only a sub-set of items was used in the calculation. These coefficients do suggest that as the project continues, reliability calculations based on the whole test might well yield acceptable numbers.

Table 1: Cronbach Alpha Coefficients for subtest A (20 test items)

\begin{tabular}{|l|c|}
\hline Group of Learners & Alpha coefficients \\
\hline Township schools & 0.148 \\
\hline Ex-Model C schools & 0.662 \\
\hline UPFY & 0.586 \\
\hline
\end{tabular}

\section{Validity}

The test instrument was validated after implementation by a panel consisting of two UPFY chemistry lecturers, three Grade 12 Physical science teachers (two from Ex-Model C schools and one from a township school), and two science education researchers from the University of Pretoria. Minor adjustments were made to a number of test items to avoid ambiguity and to strengthen weak distracters. The panel agreed that the weak characteristics of test items on Organic Chemistry resulted from the scope of questions stretching beyond the current Grade 12 Physical Science syllabus. The poor performance and weak characteristics of test items on electrochemistry reflect the fact that the topic that is generally accepted to be difficult to master for both teachers and learners. A small number of test items assessed understanding of subject content that forms part of the Grade 10 rather than the Grade 11/12 syllabus, but was judged essential pre-knowledge for tertiary education.

\section{Sample}

The composition of the sample of Grade 12 learners used for this study mimics the composition of first-year chemistry students at the University of Pretoria. The test instrument was administered at the end of the third term to all Grade 12 learners taking physical science on both standard and higher levels at three schools in privileged environments (1 English and 2 Afrikaans medium; 199 English and 234 Afrikaans learners), and four township schools (146 learners).

The University of Pretoria sponsors a Foundation Year Programme for students of good potential from previously disadvantaged communities. Learners who passed Grade 12 mathematics plus either physical science or biology on standard or higher level are selected 
after assessment of reasoning skills and proficiency in science, mathematics and English. By contrast to Grade 12 learners, UPFY students have already achieved an overall pass in Grade 12 and have complied with the criteria for selection to the programme. The UPFY programme prepares students for tertiary education by strengthening their secondary education. The performance of UPFY students upon exit of the programme can therefore be compared directly with that of Grade 12 learners upon exit from high school. The full cohort of UPFY students (185) was assessed during this study.

Grade 12 learners were assessed during August 2003 and UPFY students in October 2003. The test instrument was divided into three or four subtests depending on the time restriction imposed by each institution. As a result, each learner answered only between 20 and 30 test items. The total number of responses per test item was 47-50 for township learners, 90-155 for Ex-Model C school learners and 45-47 for UPFY students.

\section{Results and discussion}

For the purpose of drawing up a chemical concepts inventory, test items were grouped in 12 subsets covering nine chemistry content topics typically included in first-year chemistry, and three types of scientific skills. A small number of items were included in more than one subset. The performance results for the different cohorts are presented in Table 2.

Table 2: Performance of learners from township and Ex-Model C schools, and UPFY students

\begin{tabular}{|c|c|c|c|c|}
\hline \multirow{2}{*}{$\begin{array}{c}\text { Topic } \\
\text { (Subset of questions) }\end{array}$} & \multirow{2}{*}{$\begin{array}{l}\text { Number of } \\
\text { test items }\end{array}$} & \multicolumn{3}{|c|}{$\begin{array}{c}\text { Performance } \\
\text { (Average \% correct answers) }\end{array}$} \\
\hline & & $\begin{array}{l}\text { Township } \\
\text { Schools }\end{array}$ & $\begin{array}{l}\text { Ex-Model C } \\
\text { Schools }\end{array}$ & UPFY \\
\hline Atoms, ions \& molecules & 10 & $24 \%$ & $57 \%$ & $59 \%$ \\
\hline Mole concept & 7 & $27 \%$ & $52 \%$ & $53 \%$ \\
\hline Reactions & 11 & $\begin{array}{c}29 \% \\
(29 \%)^{*}\end{array}$ & $\begin{array}{c}51 \% \\
(53 \%)^{*}\end{array}$ & $\begin{array}{c}51 \% \\
(52 \%)^{*}\end{array}$ \\
\hline Phases of matter & 14 & $22 \%$ & $55 \%$ & $61 \%$ \\
\hline Solutions & 6 & $25 \%$ & $46 \%$ & $49 \%$ \\
\hline Acids \& bases & 3 & $24 \%$ & $42 \%$ & $21 \%$ \\
\hline Chemical equilibrium & 6 & $14 \%$ & $36 \%$ & $33 \%$ \\
\hline Electrochemistry & 8 & $19 \%$ & $28 \%$ & $21 \%$ \\
\hline Organic chemistry & 6 & $\begin{array}{c}23 \% \\
(34 \%)^{*}\end{array}$ & $\begin{array}{c}44 \% \\
(57 \%)^{*}\end{array}$ & $\begin{array}{c}46 \% \\
(61 \%)^{*}\end{array}$ \\
\hline Mathematical skills & 11 & $22 \%$ & $54 \%$ & $59 \%$ \\
\hline Language skills & 6 & $36 \%$ & $68 \%$ & $71 \%$ \\
\hline Process skills & 5 & $\begin{array}{l}19 \% \\
(20 \%) *\end{array}$ & $\begin{array}{c}50 \% \\
(52 \%)^{*}\end{array}$ & $\begin{array}{c}53 \% \\
(55 \%)^{*}\end{array}$ \\
\hline
\end{tabular}

* Adjusted by application of partial credit to selected open-ended items

In general, UPFY students have outperformed both Ex-Model C and township schools, except for topics that had not yet been covered at the time of assessment (acids \& bases, chemical equilibrium and electrochemistry). The performance of township schools is marginally above the random guess level in all areas, except for three topics, i.e. chemical equilibrium, where the extent of guessing was limited by the use of short answer questions, organic chemistry (where performance improved after partial credit was awarded) and test items that assessed proficiency in the language of science. The results are presented per topic in the following discussion. 


\section{Atoms, ions and molecules}

In general, respondents from UPFY and Ex-Model $\mathrm{C}$ schools displayed an acceptable mastery of the basic concepts associated with ions and molecular formulae. The answers to question A14 (Example 1), however, suggested that very few learners/students have an appropriate idea of the size of the carbon atom or the volume of a 12-gram sample of carbon the size of Avogadro's number). Another concept that could not be properly applied was periodicity, i.e. the expected similarity in chemical behaviour of atoms in the same group of the Periodic table (Item B-6, not shown).

\section{The mole concept}

Lecturers at tertiary level often assume complete mastery of the mole concept. The results of this study are warning against such an assumption. Item D-2 (Example 2) assesses the understanding of the definition of "mole". The biggest stumbling block was the term "independent units" which was misunderstood by $41 \%$ of learners/students (choice a). Mills et al. (1993) have linked the concepts "amount of substance" and "mole" as follows in an IUPAC publication: "The SI unit of amount of substance is the mole." It is the unit of the quantity that serves to count particles, and the nature of the particles must be specified. However, "amount of substance" is often misunderstood to mean the mass of the substance (Furió et al., 2000), which is evident from the choice of options (b) and (d) in Example 2. Two other known misconceptions were evident from the results obtained for other items in this subset. Krishnan \& Howe (1994) have documented that the concept "mole" is often believed to be an exclusive property of molecules and not of atoms or particles, such as electrons. UPFY lecturers have also confirmed that many of their students confused the terms "mole" and "molecule", as if "mole" is an abbreviated form of the word "molecule".

\section{Reactions}

Learners performed very well in items that used reaction equations (symbolic representations) to assess the analysis of mole ratios or the ability to balance a reaction (Item C-6, example 3). But when confronted with the challenge to draw or interpret schematic representations of reactions on microscopic level an alarming picture emerged. Test item A-5 (Example 4) exposed the inability of candidates to interpret reaction equations in terms of chemical bonding, stoichiometry, and the limiting reagent (only $8 \%$ chose the correct answer, yet $85 \%$ of all respondents were certain or almost certain that their response was correct). $63 \%$ of all candidates could not distinguish between the coefficient " 2 " and the subscript " 3 " in the product of the reaction $2 \mathrm{~S}+3 \mathrm{O}_{2} \rightarrow 2 \mathrm{SO}_{3}$ (options $\mathrm{a}+\mathrm{b}+\mathrm{e}$ ) and $81 \%$ did not conserve atoms (options $\mathrm{a}+\mathrm{c}+\mathrm{e}$ ). This result may be compared with that obtained for item A-5 during a pretest for first-year general chemistry students at Purdue University, USA (11\% correct responses, $74 \%$ confused coefficients and subscripts and $65 \%$ did not conserve atoms; Mulford \& Robinson, 2002).

\section{Phases of matter}

The test items that presented difficulties were generally those that dealt with events at the molecular level. For example, $49 \%$ of the responses to an item assessing the understanding of evaporation of water by means of schematic presentations implied the break-up of water $\left(\mathrm{H}_{2} \mathrm{O}\right)$ into its atoms $(\mathrm{H}$ and $\mathrm{O})$ or into hydrogen and oxygen molecules $\left(\mathrm{H}_{2}+\mathrm{O}_{2}\right)$ (Item A-6, options a $+b+d$, not shown). The data suggest the prevalence of the following misconceptions: Iodine molecules in the gas phase are lighter than those in the solid phase $(46 \%$ of responses to item A-12, options a + b), gas molecules become smaller when cooled ( $24 \%$ of responses to item $\mathrm{H}-$ 4 , option a), and gas molecules cling together (liquefy) upon partial cooling (33\% of responses to item $\mathrm{K}-1$, option $\mathrm{b}$ ). In the last case the information provided about the boiling point of the 
gas seems to have been ignored in reaching the conclusion. $38 \%$ of learners confused heat and temperature by stating that equal masses of water and alcohol receive the same amount of heat when they warm from $25{ }^{\circ} \mathrm{C}$ to $50{ }^{\circ} \mathrm{C}$ (Item A-16, option c). Similar results were obtained by Mulford and Robinson (2002) and Nakhleh (1993).

\section{Solutions}

Thirty-seven per cent of candidates thought that the mass of a solution of salt in water was less than the combined masses of the water and salt beforehand (Item A-4, options $a+b+c$ ). Only $32 \%$ of candidates realised that the concentration of a saturated solution will stay the same when the solvent evaporates (item A-20, option c) and only half of those choosing the correct response for item A-20 (15\%) could explain their answer in terms of the precipitation of solid material during evaporation (A-21, option b). Item H-5 assessed the ability of learners to plan an experimental procedure for the separation of one component from a mixture when the solubility of the components in different solvents is given. The poor performance on this question $(36 \%$ correct) probably reflects the limited exposure of learners to laboratory procedures.

\section{Acids and bases}

This topic was assessed with only three items of which two were schematic representations of microscopic situations. It was clear that learners were unable to link the concept of a strong or weak acid to schematic representations that depicted differences in the extent of dissociation of the acid. The best results were obtained for Ex-Model $\mathrm{C}$ learners with $34 \%$ correct responses for the weak acid $\mathrm{HF}$ (item G-1, example 5) and $42 \%$ for the strong acid $\mathrm{HCl}$ (item G-2). This result compares reasonably well with that obtained for undergraduate students at Texas Technical University (40\% and 47\%, respectively; Smith \& Metz, 1996). Smith \& Metz (1996) concluded after a qualitative study, that "many students simply memorize definitions regarding acids and bases without being able to visualize and truly comprehend the concepts." No qualitative data was collected during our study, but a similar situation is expected.

\section{Chemical equilibrium}

This topic is generally accepted to be sophisticated in nature and difficult to master, partly because of the use of confusing terminology. The situation is often oversimplified by the suggestion that the use of Le Chatelier's principle will be sufficient to solve all problems (Tyson et al., 1999). The conceptual understanding of chemical equilibrium was assessed using three sets of paired questions. Each pair consisted of a multiple-choice item followed by a short answer explanation for the choice made in the previous question. The multiple-choice items consisted of a series of schematic representations (Example 6) (Huddle, 1998). In general, test items displayed good point-biserial correlation $(0.36-0.52)$, but poor performance of learners/students (on average only a third of responses from Ex-Model C learners and UPFY students were correct). Almost half of correct answers provided for the multiple-choice questions were followed by an inadequate or incorrect explanation. It was also occasionally observed that learners could provide suitable explanations in open-ended items, but could not relate the information, which seems to have been memorised, to the schematic representations provided.

\section{Electrochemistry}

Conceptual understanding and mastery of this subject area was the lowest of all topics assessed. Eight test items assessing understanding of conduction in the electrolyte and electrical neutrality were used for this study (Ogude \& Bradley, 1994). A variety of test item formats were used, i.e. three multiple-choice questions of which two consisted of schematic 
representations of molecular events, two true/false questions followed by short answer explanations and one item where movement of charged species had to be shown by completion of a drawing of a galvanic cell. Test items showed low discrimination indexes (0.11-0.23) and poor performance (average 22\% correct). At least 32 common student misconceptions in the area of electrochemistry have been documented (Sanger \& Greenbowe, 1999). The prevalence of the following misconceptions was confirmed by the items used in this instrument:

1. Only negatively charged ions constitute a flow of current in the electrolyte and the salt bridge (Item 1d, 14\% of responses; Item I-3e, 27\% of responses).

2. Electrons can flow through aqueous solutions without assistance from the ions (Item $\mathrm{I}-1(\mathrm{~b}+\mathrm{e}), 56 \%$ of responses, Item $6 \mathrm{a}$, option c, $22 \%$ of responses).

3. Anions (or cations) in the salt bridge and the electrolyte transfer electrons from one electrode to the other (Item I-1a, 10\% of responses).

4. The salt bridge maintains electrical neutrality by ensuring that the one half-cell is positive and the other is negative (I-6, 67\% of all responses; Item I-5b, $44 \%$ of all responses, but $58 \%$ of certain + almost certain responses).

\section{Organic chemistry}

Organic chemistry constitutes a very small part of the Grade $11 / 12$ syllabus, but $30 \%$ of the syllabus of first-year chemistry at UP. It has been our impression that some teachers may decide to omit organic chemistry in order to concentrate on the rest of the Grade 12 chemistry syllabus. The purpose of the inclusion of test items on this topic was therefore to determine the extent of exposure to organic chemistry. The recognition of the alcohol functional group was considered to be a good barometer for this purpose (Item J-4). Learners from Ex-Model C schools performed reasonably well in item J-4, but learners from township schools did not. One township school clearly did not include this concept in their instruction. The most common mistake was that of classifying carboxylic acids as alcohols, probably due to the presence of an $\mathrm{OH}$ in the acid functional group $(\mathrm{COOH})$. Understanding and mastery of the more advanced concepts of structural isomerism and esterification were also assessed. The majority of learners were unable to successfully apply these concepts to the examples given (items J-5 and J-6). However, if partial credit is awarded for open-ended items J-4, J-5 and J-6 the performance of the three groups increases to 34\% (township schools), 57\% (Ex-Model C schools) and 61\% (UPFY) (Table 2). This result contradicts our initial hypothesis that organic chemistry is neglected or omitted in secondary schools, at least in those schools involved in our study.

\section{Certainty of response}

Seventy-two test items were followed by a certainty of response index (CRI) where candidates indicated on a scale of 4 their confidence about the correctness of their answer [certain (4), almost certain (3), almost a guess (2) or a totally guessed answer (1)]. The purpose of the inclusion of a CRI was to remove the "baseline noise" due to guessing during the analysis of data for the presence of misconceptions. The data was analysed in the following way: Thirtyone multiple-choice test items were chosen randomly. All responses with a "guess" or "almost a guess" indication were removed from the set and the frequency distribution for the remainder (the high CRI group) was analysed on the assumption that it would provide a more valid picture of the prevalence of specific misconceptions.

An alarming observation was made that despite poor or even dismal performance the certainty of response was high for all groups, even the township learners where lack of knowledge and guessing was prevalent. For twenty-four of the thirty-one items analysed more than $70 \%$ of respondents indicated that they were certain about the correctness of the answer provided. There was no correlation between the certainty of response and performance on individual test 
items. This finding was especially evident for Item A-5 (Example 4) where only 8\% chose the correct answer, but $85 \%$ of respondents indicated that they were certain or almost certain of the correctness of their response. Whether this result points to the debilitating presence of misconceptions or the fact that learners "do not know that they don't know" will require further investigation.

In general, the percentage of correct answers represented a larger fraction of responses for the high CRI group than for the untreated group (the percentage correct answers increased by up to $12 \%$ ). The frequency distribution per test item changed only marginally (between $1-5 \%$ ) after all the responses with a "guess" or "almost a guess" indication were removed. Only one item was found where the removal of guessed answers resulted in a pattern alteration (Item I-3). This item was atypical in the sense that two thirds of respondents admitted that they had guessed the answer. Figure 1 shows the frequency distribution for item I-3. After removal of guessed answers the number of correct answers for I-3 (option d) increased relative to the rest of the responses, and the strongest distracter is shown to be (e), not (c) as implied by the original data.

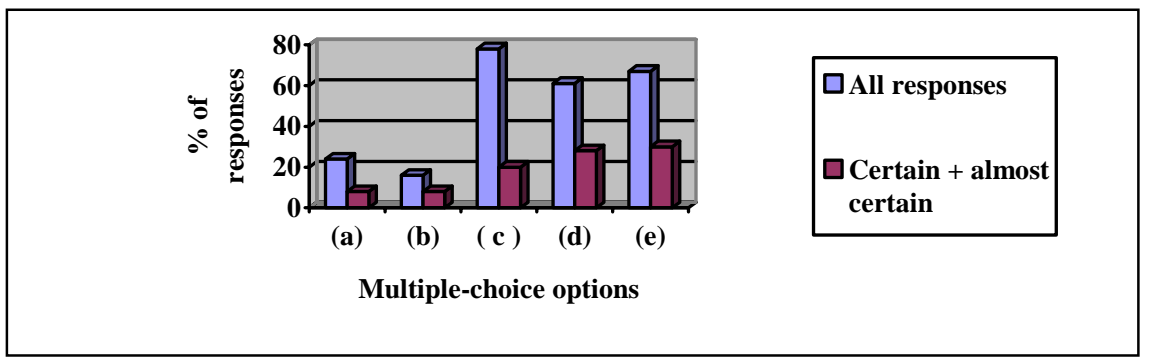

Figure 1: Frequency distribution for Item I-3

The analysis of CRI responses indicated that Grade 12 learners and UPFY students were generally over-confident about the correctness of their answers. It also showed that the guessing factor did not obscure or distort the frequency distribution of responses obtained in the multiple-choice items, except in the single case where there was a distinct lack of knowledge and understanding of the subject material.

\section{Conclusion and implications}

The results of this study remind lecturers at universities to be very careful about relying on material taught in secondary schools to act as a scaffold on which to build their courses. Upon exit from secondary education Grade 12 learners are poorly prepared for first-year chemistry in terms of conceptual understanding. For example, the mole concept is a cornerstone of first-year chemistry, but most students would require further thorough teaching at tertiary level in order to develop a deep understanding of the concept. The poor performance for all cohorts on basic concepts, such as stoichiometry and the limiting reagent, as well as in the special topics of acids and bases, chemical equilibrium, and electrochemistry also serves as a reminder that students do not have a good grounding in these topics even though these topics are covered in the secondary school syllabus. Contrary to expectations, the basic aspects of organic chemistry were covered in most of the schools involved in this study.

This study highlighted the generally poor performance of students from township schools and the significant improvement in performance after one year of intensive instruction of UPFY students who generally came from similar or more impoverished backgrounds. Upon exit from the UPFY programme students performed at least on par with their counterparts from Ex- 
Model C schools. In terms of chemistry background these students were sufficiently prepared for transfer to the mainstream first year of tertiary education.

The study has provided ample evidence that learners/students have poor representational competence. Learners were more competent in test items that used symbolic representations of chemistry (which could be solved using practised algorithms), but the interpretation of symbolic information (e.g. reaction equations) and macroscopic processes (e.g. evaporation and corrosion) in terms of events on the molecular level found them lacking. Inadequate and inaccurate models of the molecular world are suspected to be the cause for the observed poor performance in conceptual items, presented in a format with which learners/students were unfamiliar. In order to address this situation, lecturers at tertiary level will have to actively promote conceptual understanding of all basic chemical concepts and resist the temptation to teach and assess mainly procedural fluency.

This study has confirmed the prevalence of a number of well-known misconceptions in the major subject areas of first-year tertiary chemistry. No new misconceptions were identified. Self-reporting of guessed answers proved to be of little use to remove baseline noise in the analysis of multiple-choice items for the prevalence of specific misconceptions, because students were generally confident that there answers were correct or were reluctant to admit to guessing.

Of real concern, however, is the evidence of over-confidence obtained from the certainty of response analyses. This result indicates that respondents failed to judge the complexity and level of difficulty of questions accurately, probably due to a lack of knowledge and conceptual understanding. Such an overly optimistic appraisal of ability to perform a task successfully may limit reflection and re-evaluation of problem-solving approaches, resulting in poor performance. The greater use of schematic presentations in all levels of teaching and assessment may go a long way towards exposing misconceptions, the improvement of conceptual understanding, the restriction of rote learning, and the improvement of problemsolving abilities. However, further studies are required to confirm this hypothesis and to clarify the reasons for the extent of over-confidence amongst respondents.

To conclude, this study has contributed greatly towards a better insight into the extent of mastery of basic chemical concepts at secondary level, which will advise the teaching practice at first-year tertiary level. It contributed towards the refinement of a suitable test instrument for future implementation, i.e. for the monitoring of the proficiencies of incoming first-year students over the next few years.

\section{References}

Angel, S.A. \& LaLonde, D.E. (1998). Science success strategies: An interdisciplinary course for improving science and mathematics education. Journal of Chemical Education, 75, 1437-1441.

Bowen, C.W. (1998). Item design considerations for computer-based testing of student learning in chemistry. Journal of Chemical Education, 75, 1172-1175.

Bowen, C.W. \& Bunce, D.M. (1997). Testing for conceptual understanding in General Chemistry, The Chemical Educator, 2, 1-17. Article retrieved June, 2003 from http://journals.springer-ny.com/chedr.

Furió, C., Azcona, R., Guisasola, J. \& Ratcliffe, M. (2000). Difficulties in teaching the concepts of "amount of substance" and "mole". International Journal of Science Education, 22, 1285-1304. 
Hasan, S., Bagayoko, D. \& Kelley, E.L. (1999). Misconceptions and the certainty of response index (CRI). Physics Education, 34, 294-299.

Hoy, A.W. (2004). What so teachers need to know about self-efficacy? Paper presented at the American Educational Research Association annual meeting in San Diego, CA.

Huddle, B.P. (1998). "Conceptual Questions" on LeChâtelier's principle. Journal of Chemical Education, 75,1175 .

Johnstone, A.H. \& El-Banna (1986). Capacities, demands and processes - A predictive model for science education in chemistry. Education in Chemistry, 23, 80-84.

Kozma, R. \& Russell, J. (1997). Multimedia and understanding: Expert and novice responses to different representations of chemical phenomena. Journal of Research in Science Teaching, 34, 949-968.

Krishnan, S.R. \& Howe, A.C. (1994). The mole concept. Journal of Chemical Education, 71, 653-655.

Lijnse, P.L., Licht, P., Waarlo, A.J. \& de Vos, W. (1990). Relating macroscopic phenomena to microscopic particles. Proceedings of Conference at Utrecht Centre for Science and Mathematics Education, University of Utrecht, and references therein.

Lythcott, J. (1990). Problem solving and requisite knowledge of chemistry. Journal of Chemical Education, 67, 248-252.

McFate, C. \& Olmsted III, J. (1999). Assessing student preparation through placement tests. Journal of Chemical Education, 76, 562-565.

Mills, I.M., Cvitas, T., Homann, K., Kallay, N. \& Kuchitsu, K. (1993). IUPAC, Quantities, units and symbols in physical chemistry (Oxford: Blackwell).

Mulford, D. R. \& Robinson, W. R. (2002). An inventory for alternate conceptions among first-semester General Chemistry students. Journal of Chemical Education, 79, 739-744.

Nakhleh, M.B. (1993). Are our students conceptual thinkers or algorithmic problem solvers? Journal of Chemical Education, 701, 52-55.

Ogude, A.N. \& Bradley, J.D. (1994). Ionic conduction and electrical neutrality in operating electrochemical cells. Journal of Chemical Education, 71, 29-34.

Pajares, F. (1997). Current directions in self-efficacy research. In M. Maehr \& P.R. Pintrich (Eds), Advances in motivation and achievement (Vol. 10, pp. 1-49). Greenwich, CT: JAI Press.

Sanger, M.J. \& Greenbowe, T.J. (1999). An analysis of college chemistry textbooks as sources of misconceptions and errors in electrochemistry. Journal of Chemical Education, 76, 853-860.

Smith, K.J. \& Metz, P.A. (1996), Evaluating student understanding of solution chemistry through microscopic representations. Journal of Chemical Education, 73, 233-235.

Treagust, D.F. (1988). Development and use of diagnostic tests to evaluate students' misconceptions in science. International Journal of Science Education, 10, 159-169.

Tyson, L., Treagust, D.F. \& Bucat, R.B. (1999). The complexity of teaching and learning chemical equilibrium. Journal of Chemical Education, 76, 554-558.

Voska, K.W. \& Heikkinen, H.W. (2000). Identification and analysis of student conceptions used to solve chemical equilibrium problems. Journal of Research in Science Teaching, 37, 160-176. 
Chemical concepts inventory of Grade 12 learners

Wagner, E.P., Sasser, H. \& DiBiase, W.J. (2002). Predicting students at risk in General Chemistry using pre-semester assessment and demographic information. Journal of Chemical Education, 79, 749-755.

Yarroch, W.L. (1985). Student understanding of chemical equation balancing. Journal of Research in Science Teaching, 22, 449-459.

Zoller, U., Dori, Y.F. \& Lubezky, A. (2002). Algorithmic, LOCS and HOCS (chemistry) exam questions: performance and attitudes of college students. International Journal of Science Education, 24, 185-203. 


\section{Appendix: Examples from the test}

** indicates the correct answer

Example 1 (Item A-14):

What is the approximate number of carbon atoms it would take placed next to each other to make a line that would cross this dot:
(a) 4
(b) $\quad 200$
(c)** $\quad 30000000$
(d) $\quad 6,02 \times 10^{23}$
(10\% of responses)
(6\% of responses)
( $10 \%$ of responses)
( $74 \%$ of responses)

Example 2 (Item D-2):

One mole of oxygen molecules contains more independent units $\left(\mathrm{O}_{2}\right)$ than one mole of oxygen atoms $(\mathrm{O})$.
(a) True, because there are two atoms of $\mathrm{O}$ for every molecule of $\mathrm{O}_{2}$.
( $41 \%$ of responses)
(b) True, because one mole of $\mathrm{O}_{2}$ weighs more than one mole of $\mathrm{O}$.
( $23 \%$ of responses)
(c) ${ }^{* *}$ False, because both of them have the same number of particles.
( $24 \%$ of responses)
(d) False, because one mole of $\mathrm{O}$ has the same mass as one mole of $\mathrm{O}_{2}$.
(11\% of responses)

\section{Example 3 (Item C-6):}

The reaction of carbon and hydrogen to form ethane can be presented by the chemical equation

$$
x \mathrm{C}+y \mathrm{H}_{2} \rightarrow \mathrm{zC}_{2} \mathrm{H}_{6}
$$

This equation is properly balanced when the values of $x, y$, and $z$ are
(a) $1,1,1$
(b)** $2,3,1$
( $5 \%$ of responses)
(c) $2,6,1$
( $77 \%$ of responses)
( $8 \%$ of responses)
(d) $1,3,1$
( $2 \%$ of responses)
(e) none of these
( $8 \%$ of responses)

Example 4 (Item A-5):

The diagram represents a mixture of $\mathrm{S}$ atoms and $\mathrm{O}_{2}$ molecules in a closed container.

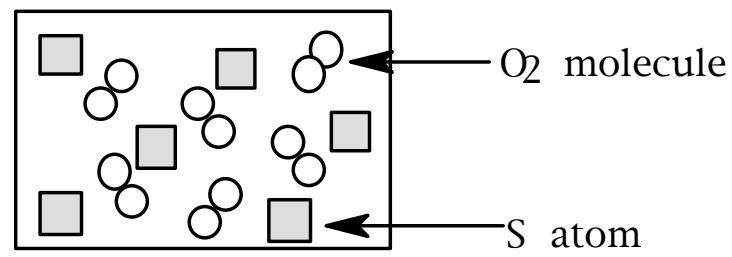

Which diagram shows the results after the mixture reacts as completely as possible according to the equation $2 \mathrm{~S}+3 \mathrm{O}_{2} \rightarrow 2 \mathrm{SO}_{3}$ ?

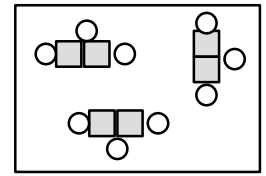

(a) $(9 \%)$ $(14 \%)^{\#}$

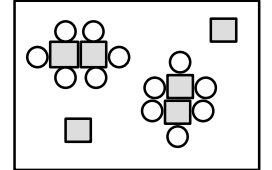

(b) $(10 \%)$ $(23 \%)^{\#}$

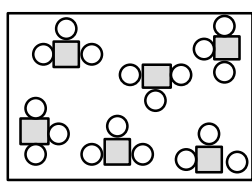

(c) $(28 \%)$ $(15 \%)^{\#}$

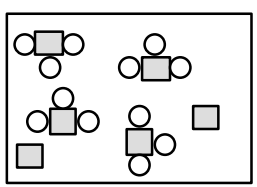

$(\mathrm{d})^{* *}(8 \%)$ $(11 \%)^{\#}$

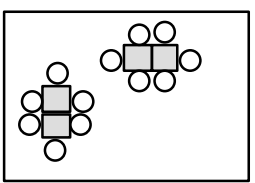

(e) $(44 \%)$ $(37 \%)^{\#}$

\# Results obtained by Mulford \& Robinson (2002) 
Example 5 (Item G-1):

Hydrofluoric acid, HF, is considered a weak acid. Which microscopic representation best illustrates this concept?

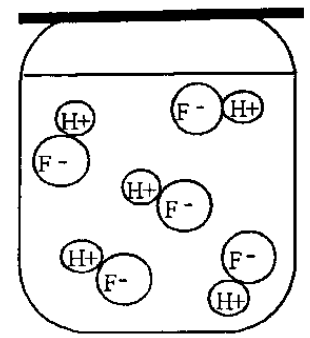

(A)

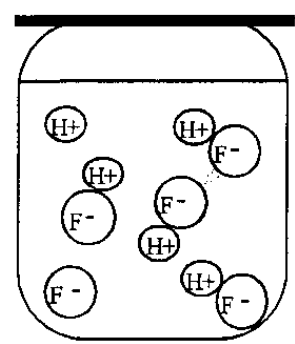

(B)

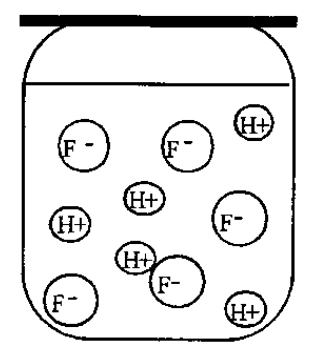

(C)

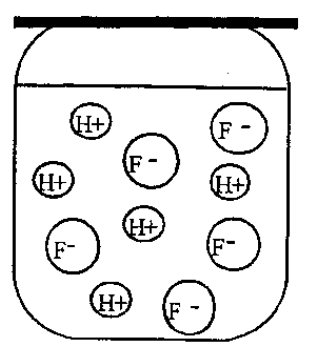

(D)

Responses: (28\%)

$(28 \%)^{* *}$

$(20 \%)$

$(25 \%)$

Example 6 (Item E-1):

The exothermic reaction $\bigcirc(\mathrm{g}) \longleftrightarrow \bullet$ (g) was allowed to come to equilibrium, as represented by the box below:

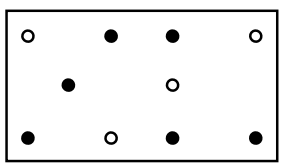

Equilibrium system

Some - was added to the system at equilibrium. Which box $(\mathrm{A}-\mathrm{E})$ best represents the new position of equilibrium?

Box A

Box B

Box C

Box D

Box E

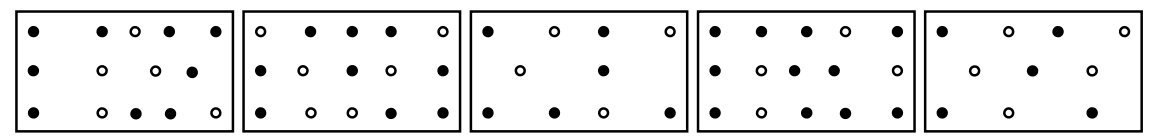

Responses: $(6 \%)$

$(35 \%) * *$

$(13 \%)$

$(24 \%)$

(22\%) 